\section{Different Strokes}

\section{Need for Help Among Stroke-affected Persons in British Columbia}

\author{
Denise S. Cloutier-Fisher, PhD
}

\section{ABSTRACT}

Background: Cerebrovascular disease (CD) is a leading cause of disability and death in British Columbia, as in much of the developed world. Provision of care for stroke-affected persons depends upon accurate estimates of prevalence, but also on a clearer understanding of the specific characteristics and needs of this population.

Methods: Data are drawn from the Canadian Community Health Survey, Cycle 1.1, 20002001. Bivariate analysis examines older populations age 55+ living in BC to determine how stroke-affected persons differ from non-stroke-affected persons according to sociodemographic factors, health, co-morbid conditions, need for help, and service use. Multivariate logistic regression was used to assess the impact of stroke status on need for help with regular and instrumental activities of daily living.

Results: Risk of stroke rises every decade after age 55. The prevalence of CD in British Columbia is $3.7 \%$ among those age $55+$ and $5.2 \%$ among those age $65+$. Stroke survivors use more acute care services (i.e., they spend more nights in hospital and consult physicians more often on an annual basis). Being older and female, as well as having lower income and poor health are characteristics of stroke survivors. Even after controlling for these variables, the odds of needing help with regular tasks of daily living are still higher for stroke-affected persons because of the high level of disability associated with stroke.

Conclusion: Ultimately, while it is appropriate to target acute care resources to treat stroke and to minimize negative stroke outcomes, these data support the need to develop a clearer understanding of the needs and service utilization patterns of community-dwelling stroke survivors to ensure access to a full continuum of care.

MeSH terms: British Columbia; cerebrovascular disease; stroke; need; service use

La traduction du résumé se trouve à la fin de l'article.

Assistant Professor, Department of Geography/Centre on Aging, University of Victoria, Victoria, BC Correspondence: Denise S. Cloutier-Fisher, P.O. Box 1700, Station CSC, Victoria, BC V8W 2Y2, Tel: 250-721-6289, Fax: 250-721-6499, E-mail: dcfisher@uvic.ca

Acknowledgements: The author is grateful to Dr. Colin Reid, Ms. Diane Allan, Ms. Jodi Sturge and anonymous reviewers on the first submission; and to Dr. Zheng Wu for comments on the second draft of this manuscript.

Source of support: This research has received support from a CIHR research grant \# 53070-MOP.
C erebrovascular disease (CD) is a major public health problem worldwide and a leading cause of death and disability in British Columbia. ${ }^{1-3}$ While mortality rates due to ischemic heart disease and acute myocardial infarction have been decreasing over time, mortality rates for stroke have not changed significantly in the past 10 years, accounting for $7 \%$ of all-cause mortality. ${ }^{3}$ Conservative estimates suggest that each year approximately 50,000 strokes occur in Canada, but recent research in the United States that examined hospital administrative data, suggests that this number may be conservative. ${ }^{4,5}$ Currently, there are an estimated 300,000-350,000 stroke survivors in Canada. ${ }^{2-5}$ Recent, population-based surveys suggest that the prevalence of stroke among community residents in Canada is between 5.2-6.3\% among those age 65 and over., ${ }^{5,6}$ Better surveillance systems are needed in order to improve the accuracy of estimates regarding the incidence and prevalence of this disease in Canada. ${ }^{7-10}$ Furthermore, such estimates do not take into account the rates of stroke among harder-to-reach populations, such as those who are institutionalized, and persons living on reserves and on army bases. $^{11}$

The need to focus attention on CD comes from an awareness of the high burden of disability associated with this disease and from projections that suggest that rates of stroke are expected to rise over the next 15 years due to population aging. ${ }^{5}$ About $60 \%$ of stroke survivors experience neurological deficits that require rehabilitation and 20\% require long-term or temporary institutionalization. ${ }^{12}$ Stroke affects individuals differently and each stroke can result in a wide range of disabilities, including: arm or leg paralysis, difficulty with walking, speech, vision, reading, writing, and cognition, as well as depression, memory loss and personality change. ${ }^{12-15}$ Not surprisingly, the overall burden of stroke can result in pronounced psychological, physical and financial impacts for some individuals, families, the health care system, and society as a whole. ${ }^{15}$

Limited research has aimed at understanding the needs of stroke-affected persons living in the community despite the high level of disability associated with this disease, and the relationship between disability and need for help. ${ }^{16}$ This study 
TABLE I

Bivariate Profiles: Selected Characteristics of Stroke Survivors and Non-stroke-affected Individuals Age 55 and Over in British Columbia

Characterisic/Risk Factor
Sex**
Men
Women
Age**
$55-74$
$75+$
Marital Status*
$\%$ married
\% not married
Income**
Low income
Middle to higher
Education**
$\leq$ secondary
$\geq$ post secondary
Health**
\% fair or poor
\% excellent, very good or good
High Blood Pressure*
Yes
No
Diabetes*
Yes
No
Heart Disease*
Yes
No
Mean Chronic Conditions***
Mean Nights in Hospital ***
Mean Physician Consults***
Mean Pho

\begin{tabular}{|c|c|}
\hline \multicolumn{2}{|c|}{ Reporting Effects of Stroke } \\
\hline Number & $\%(95 \% \mathrm{CI})$ \\
\hline 16,800 & $52(42-62)$ \\
\hline 15,400 & $48(38-58)$ \\
\hline 16,000 & $50(40-60)$ \\
\hline 16,200 & $50(40-60)$ \\
\hline 18,800 & $58(49-68)$ \\
\hline 13,400 & $42(32-52)$ \\
\hline $5300 \dagger$ & $19(11-28)$ \\
\hline 22,000 & $81(72-89)$ \\
\hline 20,800 & $66(54-77)$ \\
\hline 10,900 & $19(11-27)$ \\
\hline 21,500 & $67(58-76)$ \\
\hline 10,500 & $33(24-42)$ \\
\hline 17,900 & $56(48-64)$ \\
\hline 14,200 & $44(34-54)$ \\
\hline $8000 \dagger$ & $25(16-33)$ \\
\hline 4,200 & \\
\hline 14,900 & $46(37-56)$ \\
\hline 17,300 & $54(43-64)$ \\
\hline 31,000 & $4.17(4.16-4.18)$ \\
\hline 31,700 & $4.25(4.15,4.35)$ \\
\hline 31,900 & $8.75(8.66-8.84$ \\
\hline
\end{tabular}

$\begin{array}{cc}\begin{array}{c}\text { Not Reporting Effects of Stroke } \\ \text { Number }\end{array} & (\mathbf{9 5} \% \mathbf{C I}) \\ 396,300 & 47(45-49) \\ 445,800 & 53(51-55) \\ 654,700 & 78(76-80) \\ 187,350 & 22(20-24) \\ 589,900 & 70(68-72) \\ 252,200 & 30(28-32) \\ 87,800 & 12(11-14) \\ 630,500 & 88(86-89) \\ 403,500 & 49(47-51) \\ 424,400 & 51(49-53) \\ 181,300 & 22(20-23) \\ 660,100 & 78(77-80) \\ & \\ 241,784 & 29(27-31) \\ 599,100 & 71(69-73) \\ 79,000 & 9(8-10) \\ 762,100 & 91(89-92) \\ 105,500 & 12(11-14) \\ 735,900 & 88(86-89) \\ 827,300 & 2.08(2.08-2.09) \\ 840,700 & 0.85(0.84-0.86) \\ 838,700 & 4.61(4.60-4.62)\end{array}$

Source: CCHS, $1.12000 / 01$

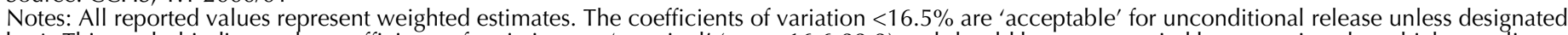

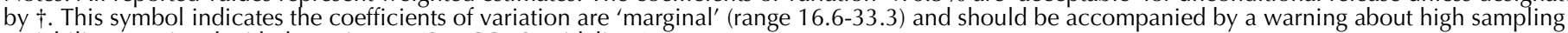
variability associated with the estimates (See CCHS guidelines).

* statistically significant chi-square test results $(95 \%)$

** $\quad$ statistically significant chi-square results $(99 \%)$

$* * *$ statistically significant t-test results $(95 \%)$

examines need for help among communitydwelling stroke survivors. While access to timely stroke care provided by highly trained, interdisciplinary stroke teams is critical to reduce the negative impacts of stroke when it occurs and to promote improved functional outcomes, a focus on acute care exclusively obscures the importance of the specific daily needs of stroke survivors. ${ }^{14-16}$ Ensuring that a broad range of appropriate home care and communitybased services are in place for stroke survivors and their families can promote positive rehabilitation outcomes, enhance wellbeing, reduce social isolation and prevent recurrent strokes. ${ }^{15-17}$

Health care restructuring initiatives in British Columbia (BC), as in other jurisdictions, recognize the importance of providing care closer to home for individuals. ${ }^{17}$ Nevertheless, the majority of funding is still directed at institutional care rather than health promotion and primary prevention activities, public health nursing and inspections, nutrition, speech and hearing programs. ${ }^{17}$ These are the kinds of services that are needed by stroke-affected persons and other vulnerable populations. ${ }^{15-17}$ The province of $\mathrm{BC}$ is of interest because it has a population that is aging more rapidly than other Canadian provinces. ${ }^{18}$ The present study develops profiles of community-dwelling stroke survivors and non stroke-affected persons in BC using data collected from the Canadian Community Health Survey (CCHS), Version 1.1. Multivariate logistic regression analyses are run to examine whether being stroke-affected is an important factor in elevating the need for help among the age 55 and over population when age, gender, health and morbidity are taken into account. Other population-based Canadian research has focussed on risk factors for stroke (e.g., age, gender and comorbid conditions), and elaborated on the patterns and predictors of well-being among stroke survivors. ${ }^{5,6}$ This project focusses on need for help among communitydwelling stroke-affected persons. These results are a starting point for more indepth, follow-up qualitative analyses of the needs and supports of stroke survivors, an identified need in the literature. ${ }^{12-17}$
METHODS

Data from the Canadian Community Health Survey (CCHS) are employed to develop comparative profiles of strokeaffected and non-stroke-affected persons in $\mathrm{BC}$ and to conduct a multivariate analysis examining need for help among the 55+ population. The CCHS represents the perspectives of $98 \%$ of Canadians. It is a large, random stratified household survey of the Canadian population age 12 and over who live in the ten provinces and the three territories, and was designed to allow comparisons to be made across health regions in Canada and BC. ${ }^{19}$ This crosssectional survey includes data from 5,672 respondents age 55 and over living in $\mathrm{BC}$. The weighted total represents 876,452 British Columbians age 55 and over. Children and the elderly were oversampled. In this survey, an unweighted total of 219 persons age 55 or over indicated that they suffer from the effects of a stroke. (Definitions of variables used in the analysis are available from the author upon request.) Chi-square tests and confidence 
TABLE II

Bivariate Profiles: Need for Help Among Stroke Survivors and Non-stroke-affected Individuals Age 55+

\begin{tabular}{|c|c|c|c|c|}
\hline \multirow[t]{2}{*}{ Characteristic } & \multicolumn{2}{|c|}{$\begin{array}{c}\text { Reporting } \\
\text { Effects of Stroke }\end{array}$} & \multicolumn{2}{|c|}{$\begin{array}{c}\text { Not Reporting } \\
\text { Effects of Stroke }\end{array}$} \\
\hline & Number & & & $\%(95 \% \mathrm{Cl})$ \\
\hline Needs help with at least one task & & & & \\
\hline $\begin{array}{l}\text { Yes* } \\
\text { No* }\end{array}$ & 23,600 & $73(64-82)$ & 228,900 & $27(25-29)$ \\
\hline $\begin{array}{l}\text { No * } \\
\text { Needs help preparing meals }\end{array}$ & $8600 \dagger$ & 27 & 11,300 & $73(71-75)$ \\
\hline Needs help prep & & & & \\
\hline Yes * & 11,200 & $35(25-44)$ & 48,300 & $6(5-7)$ \\
\hline No ${ }^{*}$ & 21,000 & $65(56-74)$ & 793,300 & $94(93-96)$ \\
\hline Need help with personal care & & & & \\
\hline Yes * & 8100 & $25(17-34)$ & 27,300 & $3(2-4)$ \\
\hline No ${ }^{*}$ & 24,000 & $75(66-84)$ & 814,200 & $97(95-98)$ \\
\hline Needs help with everyday housework & & & & \\
\hline Yes * & 17,600 & $55(45-64)$ & 101,900 & $12(11-13)$ \\
\hline No ${ }^{*}$ & 14,600 & $45(35-56)$ & 739,700 & $88(87-89)$ \\
\hline Needs help with shopping for necessities & & & & \\
\hline Yes * & 15,300 & $48(38-58)$ & 73,400 & $9(8-10)$ \\
\hline No ${ }^{*}$ & 16,800 & $52(42-63)$ & 767,800 & $91(90-93)$ \\
\hline Needs help with heavy household chores` & & & & \\
\hline Yes * & 22,100 & $69(60-78)$ & 218,000 & $26(24-28)$ \\
\hline No ${ }^{*}$ & 10,000 & $31(22-40)$ & 622,200 & $74(72-76)$ \\
\hline Needs help moving around house & & & & \\
\hline Yes * & $7100 \dagger$ & $22(14-31)$ & 26,700 & $3(2-4)$ \\
\hline No ${ }^{*}$ & 25,000 & $78(68-87)$ & 814,900 & $97(95-98)$ \\
\hline
\end{tabular}

Source: CCHS, 1.1, 2000/01

Notes: All reported values represent weighted estimates. The coefficients of variation $<16.5 \%$ are

acceptable for unconditional release unless otherwise indicated. (See CCHS guidelines.)

$*$ indicates statistically significant chi-square result at the $95 \%$ confidence level

$\dagger$ marginal estimate with high sampling variability

intervals are given for all bivariate comparisons. T-tests were carried out to examine the differences between stroke-affected persons and others measured by the continuous variables, i.e., number of chronic conditions, number of nights spent in hospital and number of physician contacts. For the multivariate logistic regression analysis, three logistic regression models were run to estimate the odds of individuals needing help with at least one daily task. The need for help measure takes into account a mixture of activities of daily living (ADLs, e.g., personal care and moving around the house) and instrumental activities of daily living (IADLs, e.g., help with meals, and help with normal everyday housework). Stroke-affected status was entered first, then socio-economic control variables (i.e., age, gender, marital status, education and income) were added to the second model to determine their influence on need for help. Health and co-morbid conditions were added to the third model.

\section{RESULTS}

The prevalence of stroke is $3.7 \%$ among British Columbians age 55 and older, and $5.2 \%$ among those age 65 and over. From the CCHS, the prevalence rates for the Canadian population age $55+$ and age $65+$ are $3.4 \%$ and $4.9 \%$, respectively. Thus,
$\mathrm{BC}$ has somewhat higher cerebrovascular disease prevalence rates than the rest of Canada.

\section{Bivariate comparisons}

Tables I and II reveal significant differences between stroke survivors and non-strokeaffected persons on a range of variables including: age, gender, marital status, income and education, health, service use, and need for help. Stroke survivors are much more likely to be older, i.e., in the $75+$ age group rather than the 55-74 age group $(50 \%$ vs. $22 \%, \mathrm{p} \leq 0.05)$ and are more likely to be male $(52 \%$ vs. $47 \%$, $\mathrm{p} \leq 0.01)$. In addition, stroke survivors are somewhat less likely to be married $(58 \%$ vs. $70 \%, \mathrm{p} \leq 0.05)$, more likely to have low income ( $19 \%$ vs. $12 \%, \mathrm{p} \leq 0.05)$, and more likely to have an educational background of less than or equal to secondary education ( $66 \%$ vs. $49 \%, \mathrm{p} \leq 0.05)$. With respect to health status, strong differences emerge with stroke survivors being three times more likely to report fair or poor health status than non-stroke-affected persons $(67 \%$ vs. $22 \%, \mathrm{p} \leq 0.05)$. In terms of health conditions and health status, stroke survivors indicate having twice as many chronic conditions as non-stroke-affected persons (4.2 vs. $2.1, \mathrm{p} \leq 0.05$ ). On average, strokeaffected persons spend more nights in hospital ( 4.2 vs. $0.85 \%, p \leq 0.05)$ and see their fam- ily doctor with greater frequency than nonstroke-affected persons (8.8 vs. $4.6, \mathrm{p} \leq 0.05$ ).

Need for help variables (Table II) reveal that a significantly higher proportion of stroke survivors need help with at least one daily task $(73 \%$ vs. $27 \%, \mathrm{p} \leq 0.05)$. With specific tasks, stroke survivors are more likely than non-stroke-affected persons to express needing help with heavy household chores $(69 \%$ vs. $26 \%, \mathrm{p} \leq 0.05)$, followed by help with everyday housework ( $55 \%$ vs. $12 \%, \mathrm{p} \leq 0.05)$ and help with shopping for necessities ( $48 \%$ vs. $9 \%, \mathrm{p} \leq 0.05$ ).

\section{Multivariate analyses}

Standard multiple logistic regression analysis was carried out to examine the relationship between the dependent variable (i.e., need for help) and the independent variables (i.e., stroke status, socio-demographic factors, health status and co-morbidities). Service use is not added to the model as need for help predicts service use rather than the other way around. Results of the multivariate analysis are shown in Table III.

\section{The logistic regression models: Impact of stroke-affected status, socio-economic characteristics and health on need for help}

In Model 1, the odds of needing help increase among those who suffer from the effects of stroke. Adding the control variables in Model 2 reveals that stroke-affected status still increases the odds of needing help; but being in an older age group and being female are associated with greater odds of needing help with regular tasks. In Model 2, only the lower income categories increase the odds of needing help. In Model 3, only the very lowest category of income adequacy increases the odds of needing help. In addition, having good, fair or poor health status increases the odds of needing help, as does a higher number of chronic conditions. Interestingly, high blood pressure, the most common risk factor for stroke, decreases the odds of needing help.

To sum up, the likelihood of being stroke-affected and needing help decreases across the models, but is still significant in Model $3(\mathrm{OR}=2.2$; $\mathrm{CI}=1.4-3.3)$. Older age is consistently important in increasing the odds of needing help (i.e., age 75-79; $\mathrm{OR}=3.2 ; \mathrm{CI}=2.4-4.3$ and age $80+$; $\mathrm{OR}=6.9 ; \mathrm{CI}=5 \cdot 2-9.2)$ and decreasing 
TABLE III

Multiple Logistic Regression Results of Need for Help

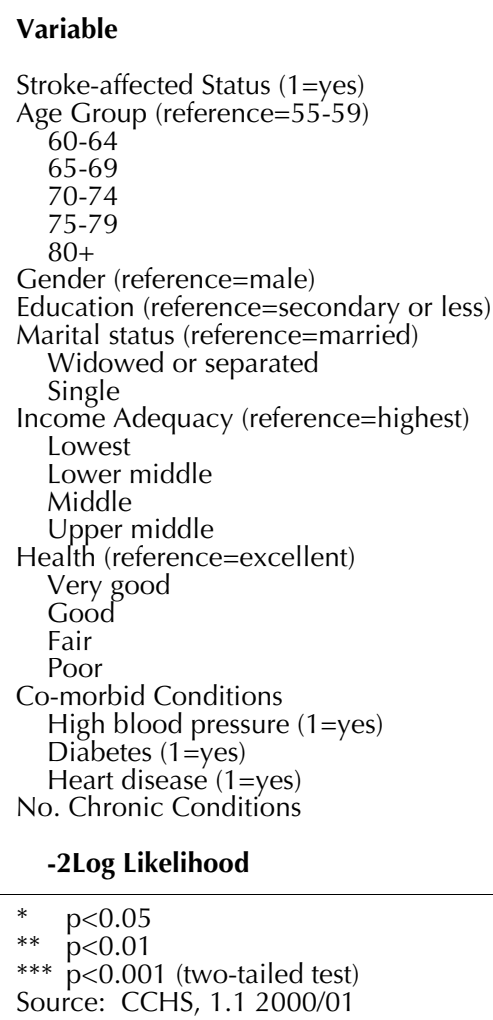

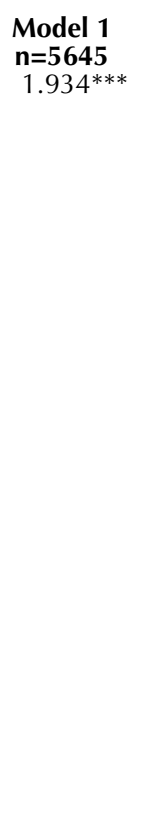

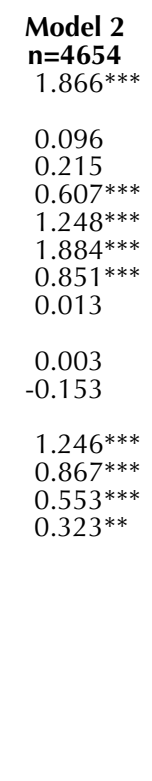

6932.3

4916.400

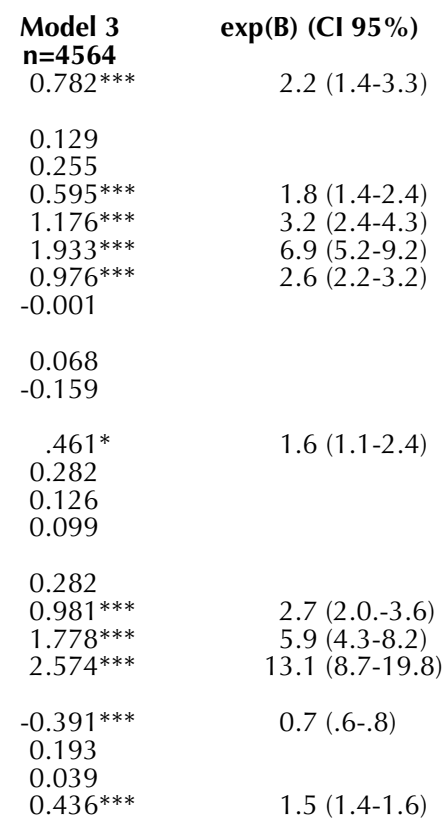

3969.4 health status increases the odds of needing help (poor; $\mathrm{OR}=13.1 ; \mathrm{CI}=8.7-19.8$ ). The number of chronic conditions is significant in increasing the odds of needing help $(\mathrm{OR}=1.5 ; \mathrm{CI}=1.4-1.6)$, however the type of co-morbid condition (i.e., diabetes or heart disease) is not significantly associated with increased need for help, and having high blood pressure, as already mentioned, actually reduces the likelihood of needing help with regular daily activities $(\mathrm{OR}=0.7$; $\mathrm{CI}=0.6-0.8$ ). Successive models (Model 1Model 3), exhibit a reduction in log likelihood values (Table III) and therefore support that there are significant relationship(s) between the dependent variable and the selected independent variables.

\section{DISCUSSION}

Even after controlling for age, gender, income and health variables, stroke-affected status is still significant and increases the odds of needing help on a daily basis, while other co-morbid conditions such as diabetes and having other heart disease do not show an effect on need for help. High blood pressure appears to decrease the odds of needing help, which may be related to the fact that hypertension is a medical condition that can be properly treated with medication so that it does not have a large or debilitating impact on daily routines. As expected, the odds of needing help with daily tasks increase for those who are in an older age group, who are female and who are in the lowest income adequacy category. Similarly, declining health status and an increase in number of chronic conditions increase the odds of needing help. Overall, the level of disability associated with stroke makes it distinctive from many other health conditions and increases the vulnerability of individuals living with this disease because of their higher level of need for help on a daily basis.

Effective stroke care requires the integrated efforts of a team ranging from health professionals such as: public health nurses, physicians, specialists, therapists and counselors through to: informal caregivers, spouses and family members. For those living with the effects of stroke, access to a broad continuum of home and community support services may help them to meet their short- and long-term needs. More research is needed to understand the full range of services accessed by stroke-affected persons, including alterna- tive practitioners and home care services. In the CCHS, low numbers of the former and a complete lack of information on home care service use* (i.e., it is optional content) pose problems in developing a clear picture of the full spectrum of services needed by stroke-affected persons. Without more complete information, it is difficult to assess whether low levels of use of non-acute services (e.g., mental health and alternative practitioners) among the population age $55+$ illustrate a lack of awareness of available supportive services, limited availability, user fees, restrictive eligibility criteria, or other factors.

It is critical to have better estimates of the prevalence of $\mathrm{CD}$ and to determine if the burden of stroke in Canada is as large as recent data from the United States would suggest. ${ }^{4}$ As a source of data, a limitation of the CCHS is that it appears to underestimate the prevalence of $\mathrm{CD}$ and stroke by failing to take into account populations living in institutions, as well as

\footnotetext{
In the CCHS, all provinces have access to common or core content with the option of requesting that additional content be added according to the specific (buy-in) needs of provincial and local health regions. Information on home care service use was not requested and thus is not available in the BC data.
} 
those living on reserves or on army bases. A further limitation of the CCHS survey is that the data are self-reported and therefore not verified by health practitioners, which complicates understanding the magnitude of the illness and the range of services required.

To address the service needs of stroke survivors and promote quality of life, it is also important to gather specific data related to the age at which the stroke occurred (also optional content), the type of stroke, the degree of impairment, whether this is the first stroke or a recurrent stroke, and level of informal support that is available. Ongoing research that triangulates data sources such as the CCHS with data from the $\mathrm{BC}$ linked health database and with qualitative interviews with communitydwelling stroke survivors will help to ensure that necessary services are available to allow stroke survivors to remain in their own homes in the community for as long as possible.

\section{REFERENCES}

1. Heart and Stroke Foundation of Canada. Heart disease and stroke in Canada. Collaboration with Health Canada, Laboratory Centre for Disease Control, Statistics Canada, University of Saskatchewan. Ottawa, 1997.

2. Heart and Stroke Foundation of Canada. The changing face of heart disease and stroke in Canada. Ottawa, 1999. ISBN 1-896242-28-6.

3. Kalache A, Aboderin I. Stroke: The global burden. Health Policy and Planning 1995;10(1):1-21.

4. Rhys Williams $\mathrm{G}$. Incidence and characteristics of total stroke in the United States. BMC Neurology 2001;1:2, http://www.biomedcentral.com/14712377/1-2.

5. Hodgson C. Prevalence and disabilities of community-living seniors who report the effects of stroke. CMAJ 1998;159(6 Suppl):S9-S14.

6. Clarke P, Marshall V, Black SE, Colantonio A. Well-being after stroke in Canadian seniors. Stroke 2002;33(4):1016-21.
7. Hakim AM, Silver F, Hodgson C. Is Canada falling behind international standards for stroke care? CMAJ 1998;159:671-73.

8. Johnson KC, Yang M. National Stroke surveillance program needed in Canada. (Letters) CMAJ 2001;165(7):165.

9. Wielgosz AT. Establishing surveillance of cardiovascular disease incidence in Canada. Can J Cardiol 1992;8(3):249-51.

10. Wilson E, Taylor G, Phillips S, Stewart PJ, Dickinson G, Ramsden VR, et al. Creating a Canadian stroke system. CMAJ 2001;164(13):1853-55.

11. CCHS, Canadian Community Health Survey, Version 1.1; Public Use Microdata File, Statistics Canada; 2000-2001.

12. Molnar-Szakacs H, Carew M. Stroke in Canada: The need for a new approach (Editorial). Can I Public Health 2000;91(6):405-6.

13. Stroke Rehabilitation Consensus Panel Report. Submitted to the Stroke Strategy Steering Committee, Heart and Stroke Foundation of Ontario, May 2000.

14. Stroke Recovery Association of BC. Partners in recovery: Case summary, no date.
15. Hakim AM, Solver F, Hodgson C. Organized stroke care: A new era in stroke prevention and treatment. CMAJ 1998;159(6 suppl):671-73.

16. Williams J, Lyons B, Rowland D. Unmet longterm care needs of elderly people in the community: A review of the literature. Home Health Care Services Q 1997;16:93-119.

17. Closer to Home. Royal Commission on Health Care and Costs, Victoria, British Columbia, 1991.

18. Northcott HC, Milliken P. Aging in British Columbia: Burden or benefit? Detselig Enterprises Calgary, 1998

19. CCHS, Canadian Community Health Survey, Version 1.1; Public Use Microdata File, Questionnaire and Derived Variable (DV) Specifications Documentation, Statistics Canada; 2000-2001

Received: January 13, 2004

Revisions requested: April 16, 2004 \& October 26, 2004

Revised mss: September 22, 2004 \& October 27, 2004

Accepted: November 17, 2004

\section{RÉSUME}

Contexte : Les maladies vasculaires cérébrales (MVC) sont l'une des principales causes d'incapacité et de mortalité en Colombie-Britannique, comme dans la plupart des pays développés. La prestation de soins aux victimes d'accidents vasculaires cérébraux (AVC) dépend de la précision des estimations de prévalence, mais aussi d'une compréhension plus claire des caractéristiques et des besoins particuliers de la population visée.

Méthode : Nous avons tiré nos données de l'Enquête sur la santé dans les collectivités canadiennes, cycle 1.1 (2000-2001). Au moyen d'une analyse bivariée, nous avons examiné les populations de 55 ans et plus vivant en Colombie-Britannique pour déterminer les différences entre les personnes touchées et non touchées par un AVC selon leur profil sociodémographique, leur santé, leur comorbidité, I'aide dont elles ont besoin et leur utilisation des services de santé. Par régression logistique multivariée, nous avons évalué les incidences du fait d'avoir eu ou non un AVC sur l'aide nécessaire pour s'adonner aux activités ordinaires et instrumentales de la vie quotidienne.

Résultats : Le risque d'AVC augmente chaque décennie après l'âge de 55 ans. En ColombieBritannique, la prévalence des MVC est de 3,7\% chez les 55 ans et plus et de 5,2\% chez les 65 ans et plus. Les personnes ayant survécu à un AVC utilisent davantage de services de soins actifs (p. ex., elles passent plus de nuits à l'hôpital et consultent leur médecin plus souvent au cours de I'année). Les survivants d'AVC sont plus susceptibles d'être âgés, de sexe féminin et d'avoir un revenu inférieur et des problèmes de santé. Même en tenant compte de ces variables, la probabilité d'avoir besoin d'aide pour accomplir les tâches ordinaires de la vie quotidienne sont plus élevées pour les victimes d'AVC en raison du haut niveau d'incapacité associé aux AVC.

Conclusion : En fin de compte, bien qu'il soit approprié de cibler les ressources de soins actifs nécessaires au traitement des AVC et de réduire les conséquences négatives de ces accidents, nos données confirment la nécessité de mieux comprendre les besoins des survivants d'AVC qui résident dans la communauté et les tendances de leur utilisation des services pour faire en sorte qu'ils aient accès à toute la gamme des soins. 